\title{
Tulane
}

Tulane Economics Working Paper Series

\section{When You Know Your Neighbour Pays Taxes: Information, Peer Effects, and Tax Compliance}

\author{
James Alm \\ Department of Economics \\ Tulane University \\ jalm@tulane.edu
}

\author{
Kim M. Bloomquist \\ Taxpayer Advocate Service \\ U.S. Internal Revenue Service \\ kim.bloomquist@irs.gov
}

\author{
Michael McKee \\ Department of Economics \\ Appalachian State University \\ mckeemj@appstate.edu
}

Working Paper 1619

December 2016

\begin{abstract}
In this paper, we suggest that individuals' tax compliance behaviours are affected by the behaviour of their "neighbours", or those about whom they may have information, whom they may know, or with whom they may interact on a regular basis. Individuals are more likely to file and to report their taxes when they believe that other individuals are also filing and reporting their taxes; conversely, when individuals believe that others are cheating on their taxes, they may well become cheaters themselves. We use experimental methods to test the role of such information about peer effects on compliance behaviour. In one treatment setting, we inform individuals about the frequency that their neighbours submit a tax return. In a second treatment setting, we inform them about the number of their neighbours who are audited, together with the penalties that they pay. In both cases, we examine the impact of information on filing behaviour and also on subsequent reporting behaviour. We find that providing information on whether one's neighbours are filing returns and/or reporting income has a statistically significant and economically large impact on individual filing and reporting decisions. However, this "neighbour" information does not always improve compliance, depending on the exact content of the information.
\end{abstract}

Keywords: Tax evasion, Tax compliance, Behavioural economics, Experimental economics. JEL codes: H26, C91 


\title{
When You Know Your Neighbour Pays Taxes: Information, Peer Effects, and Tax Compliance
}

\author{
James Alm, Kim M. Bloomquist, and Michael McKee *
}

\begin{abstract}
In this paper, we suggest that individuals' tax compliance behaviours are affected by the behaviour of their "neighbours", or those about whom they may have information, whom they may know, or with whom they may interact on a regular basis. Individuals are more likely to file and to report their taxes when they believe that other individuals are also filing and reporting their taxes; conversely, when individuals believe that others are cheating on their taxes, they may well become cheaters themselves. We use experimental methods to test the role of such information about peer effects on compliance behaviour. In one treatment setting, we inform individuals about the frequency that their neighbours submit a tax return. In a second treatment setting, we inform them about the number of their neighbours who are audited, together with the penalties that they pay. In both cases, we examine the impact of information on filing behaviour and also on subsequent reporting behaviour. We find that providing information on whether one's neighbours are filing returns and/or reporting income has a statistically significant and economically large impact on individual filing and reporting decisions. However, this "neighbour" information does not always improve compliance, depending on the exact content of the information.
\end{abstract}

JEL classification: $\mathrm{H} 26$; C91

Keywords: Tax evasion; Tax compliance; Behavioural economics; Experimental economics

\section{Policy Points:}

- Tax agencies have long promoted the use of enforcement tools (e.g., audits) that reflect the "punishment" paradigm of standard deterrence theory.

- However, much recent research finds that taxpayers comply (or not) for a wide variety of additional reasons.

- This paper uses laboratory experiments to provide evidence that the level of compliance is also influenced by information about the behaviour of one's peers, or "neighbours".

- Our results suggest that providing information on one's neighbours has a significant impact on one's own compliance decisions. However, this information does not always improve compliance, depending on the exact content of the information.

- These results suggest that a "service" paradigm for tax administration, in which tax administrators also act as facilitators and providers of services, can have a positive and significant impact on compliance.

* Alm - Department of Economics, Tulane University, New Orleans, LA 70118, USA (jalm@tulane.edu); Bloomquist - Taxpayer Advocate Service, U.S. Internal Revenue Service, Washington, D.C. 20224, USA (kim.bloomquist@irs.gov); McKee - Department of Economics, Walker College of Business, Appalachian State University, Boone, NC 28608, USA 
(mckeemj@appstate.edu). This research was partially funded by the IRS (TIRNO - 07 - P 00683). The views expressed are those of the authors, and do not reflect the opinions of the Internal Revenue Service (IRS) or of any researchers working within the IRS. The software for these experiments was designed by the authors and programmed by Michael Jones of Bridgewater State University in Bridgewater, MA. Previous versions of this paper have been presented at the November 2013 conference on "Tax Compliance in Field and Laboratory Experiments" in Munich, Germany, at the 2013 Annual Meetings of the National Tax Association in Tampa, FL, and at the June 2014 conference on " $21{ }^{\text {st }}$ Century Tax Administration" in Wellington, New Zealand. We are grateful to participants at these sessions for many useful comments, especially Nadja Dwenger, Henrik Kleven, Kai Konrad, Tim Lohse, Johannes Rincke, Monica Singhal, Erik Sørensen, Benno Torgler, Nathan Murray, Yulia Paramonova, Samara Gunter, and Matt Benge. We are also grateful to the Editor and an anonymous referee for many helpful suggestions. 


\section{Introduction}

It is increasingly recognized that an individual considers multiple factors in the decision to pay - or not to pay - legally due tax obligations. One set of factors is of course the consequence of a failure to pay one's taxes. Indeed, the standard economic model of taxpayer behaviour concludes that the probability of detection and the penalty on detected evasion are the crucial factors in the individual compliance decision. However, there is much recent research that demonstrates the role of many factors beyond enforcement and that expands the basic model of compliance in a search for other factors that may better explain why people pay taxes. ${ }^{1}$ In this paper we argue that compliance can be explained, at least in part, by recognizing the often neglected role of information about peer effects in individual behaviour.

There is in fact a long tradition in psychology, as well as in economics and sociology, that emphasizes the many impacts of peer effects on behaviour. In the psychology literature, this research has examined factors such as "group norms" (Sherif, 1936), the "bandwagon effect" (Asch, 1951, 1952), “conformity” and "social influence” (Kelman, 1958), “obedience to authority" (Milgram, 1974), and the like. In economics and sociology, this work has emphasized the role of "social dilemmas" (Dawes, 1980), "social networks" (Wasserman and Faust, 1994), “tax morale" (Frey, 1997; Orviska and Hudson, 2002), "social capital” (Putnam, 2000), “moral identity" (Akerlof and Kranton, 2000), and especially “social norms” (Elster, 1989, 1999; Young, 1998); this work is also consistent with notions such as fairness, trust, appeals to patriotism or conscience, or feelings of altruism, morality, and alienation. Regardless of the specific terms that are used, all of this research concludes that the behaviour of one's peers can

\footnotetext{
${ }^{1}$ For example, see Kirchler (2007), Torgler (2007), and Alm (2012) for comprehensive surveys and discussions of the tax evasion literature, emphasizing economic and psychological aspects of decisions, as well as individual and group dimensions.
} 
exert a strong influence on one's own behaviour, at least if there is information on these peer effects.

We argue that individuals' tax compliance behaviours are affected by the behaviour of their "neighbours", or those about whom they may have information, whom they may know, or with whom they may interact on a regular basis. Individuals seem more likely to file and to report their taxes when they believe that other individuals are also filing and reporting their taxes; conversely, when individuals believe that others are cheating on their taxes, they may well become cheaters themselves. We also argue that understanding compliance behaviour requires understanding how information about one's neighbours affects two aspects of individual behaviour: the reporting decision (e.g., how much income is reported to the tax authorities) and also the logically prior filing decision (e.g., whether or not to submit a tax return). Most analyses of tax compliance focus entirely on the reporting decision, assuming implicitly that the individual has already chosen to file a return. In contrast, we examine both behavioural dimensions.

We use experimental methods to test the impact of information about peer effects on compliance behaviour. To examine these responses, we introduce in a controlled laboratory setting various policies that inform individuals about the compliance behaviour of others in their immediate group, whom we refer to as their "neighbours". In one setting, we inform individuals about the frequency that their neighbours submit a tax return. In a second setting, we inform them about the number of their neighbours who are audited, together with the penalties that they pay. In a third setting, we combine both types of information. In all cases, we examine the impact of information on filing behaviour and also on subsequent reporting behaviour. We find that providing information on whether one's neighbours are filing returns and/or reporting 
income has a statistically significant and economically large impact on individual filing and reporting decisions. However, this neighbour information does not always improve compliance, depending on the exact content of the information.

\section{Theoretical framework: Information, peer effects, and the filing and reporting decisions}

\section{The standard portfolio model of individual reporting behaviour}

Most theoretical analyses of the individual's compliance decision begin with the economics-of-crime model of Becker (1968), first applied to tax compliance by Allingham and Sandmo (1972). Here a rational individual is viewed as maximizing the expected utility of the tax evasion gamble, weighing the benefits of successful under-reporting against the risky prospect of detection and punishment; implicitly, this approach assumes that the individual has already chosen to file a return, and so it focuses on the reporting decision, or how much income to report. The individual pays taxes because he or she is afraid of getting caught and penalized if some income goes unreported. This "portfolio" approach gives the plausible and productive result that compliance depends upon audit rates and fine rates. Indeed, the central point of this approach is that an individual pays taxes because - and only because - of this fear of detection and punishment. ${ }^{2}$

More precisely, an individual who has already decided to file a tax return and report income must choose $R$, or the amount of income to report (net of any allowable tax deductions), so as to maximize expected utility:

\footnotetext{
${ }^{2}$ See Cowell (1990), Andreoni, Erard, and Feinstein (1998), Alm (1999. 2012), Slemrod and Yitzhaki (2002), Sandmo (2005), Kirchler (2007), Torgler (2007), and Sandmo (2012) for comprehensive surveys and discussions of this literature.
} 


$$
\text { Reporting Decision: } \quad E U=(1-p) U(I-t R-C)+p U(I-t R-(1+f) t(I-R)-C) \text {, }
$$

where $E$ is the expectation operator, $U()$ is the utility function, $I$ is the individual's "true" taxable income, $t$ is the tax rate on reported income, $p$ is the audit rate (or the probability that a filed tax return is selected for audit), $f$ is the penalty rate on unreported taxes, and $C$ is the financial (and time) burden of preparing and filing a tax return. Optimization of equation (1) with respect to $R$ proceeds using standard methods, and comparative statics results are easily derived.

\section{Extension to filing behaviour}

However, the individual's filing decision (or whether or not to submit a tax return) is also of interest, and has seldom been examined. Indeed, the traditional portfolio analysis of the reporting decision does not fully capture the individual's filing decision because submitting a tax return with underreported liabilities is inherently different from failing to submit a return at all. To address the filing decision, the individual must compare the expected utility from filing with optimal income reporting to the expected utility from non-filing. The risk of detection for nonfiling is likely to be significantly different from the risk for a return that is "in the system", and is termed an "enforcement rate" to distinguish it from the audit rate on filed returns; similarly, the "enforcement penalty" for failing to file a return is likely to be different (and higher) than the penalty imposed on detected underreporting. ${ }^{3}$

To address both filing and reporting decisions, we retain but modify the reporting framework developed in Erard and Ho (2001), Alm et al. (2010), and Kleven et al. (2011). Here, an individual who decides to file a tax return and report income $R$ has expected utility equal to

\footnotetext{
${ }^{3}$ In practice, it is often difficult to detect non-filers because non-filers are often unknown to the tax authorities. For example, Alm, Bahl, and Murray (1991) note that in many countries, especially developing countries, the frequency of detection is essentially zero. However, in the U.S. the Internal Revenue Service (IRS) is able to use third-party information documents to identify and locate approximately 57 percent of all non-filers that account for about 82 percent of the non-filer tax gap (Erard and Ho, 2001).
} 
equation (1). An individual who chooses not to file a tax return (and so who reports no income) has expected utility equal to:

$$
\text { Filing Decision: } \quad E U=\left(1-p^{*}\right) U(I)+p^{*} U\left(I-\left(1+f^{*}\right) t I\right) \text {. }
$$

Here $p^{*}$ is the enforcement probability that an individual with income $I$ who has not filed a return is discovered, and $f^{*}$ is the enforcement penalty imposed on detected non-filers. Note that $p^{*}$ is likely to be different (and lower) than $p$, that $f^{*}$ is likely to exceed $f$, and that an individual who does not file a return escapes the filing cost $C$. The individual thus compares the expected utility from filing and reporting the optimal $R$ in equation (1), with expected utility from not filing in equation (2), and chooses the greater.

\section{Extension to peer effects}

As discussed by Alm (2012), this framework can be easily expanded to incorporate many other relevant considerations (e.g., alternative tax and penalty functions, employer tax withholding and third-party information, public goods and other positive inducements, endogenous audit detection probabilities, labor supply decisions, tax avoidance strategies, complexity and uncertainty, and so on). We focus here on information about peer effects.

As noted earlier, there is much evidence that recognizes the many ways in which peer effects influence individual behaviour. Whether these effects work through psychology, sociology, or economics, one's own behaviour is often affected by what one's peers are doing, at least if there is information on these peer effects. We concentrate here on one aspect of such peer effects, or social norms, while recognizing that peer effects may work through many channels.

Specifically, there is much evidence that individuals are influenced by the social context in which they make decisions, rather than only the financial considerations of reporting and 
filing. For example, there appears to be what may be termed a "social norm" of tax compliance (Elster, 1989, 1999; Young, 1998). Although difficult to define precisely, a social norm can be distinguished by the feature that it is process-oriented, unlike the outcome-orientation of individual rationality. A social norm therefore represents a pattern of behaviour that is judged in a similar way by others, and is sustained in part by social approval or disapproval. Consequently, if others behave according to some socially accepted mode of behaviour, then the individual will behave appropriately; if others do not so behave, then the individual will respond in kind. The presence of a social norm is consistent with a range of conceptual frameworks from a range of disciplines, whether they rely upon bandwagon effects, conformity, social influences, obedience to authority, social capital, social networks, fairness, trust, social customs, tax morale, moral identify, appeals to patriotism or conscience, or feelings of altruism, morality, and alienation. ${ }^{4}$ Incorporating social norms suggests that, all else equal, an individual will comply as long as he or she believes that compliance is the social norm (however defined); conversely, if noncompliance becomes pervasive, then the social norm of compliance disappears. We argue

\footnotetext{
${ }^{4}$ There are many notions similar to social norms that have explored in the analysis of tax evasion. For example Schmölders (1960) argues that individuals have an intrinsic motivation to cooperate. Frey (1997) suggests that compliance depends upon an individual's tax morale. Kirchler, Hoelzl, and Wahl (2008) explore the interaction between enforcement effort (power) and facilitation (trust) on the part of the tax authority via a slippery slope framework. McBarnet (2004) suggests that people may choose to comply willingly (what she terms committed compliance), they may choose to comply unwillingly (capitulative compliance), they may take full advantage of the law in minimizing their taxes (creative compliance), or they may choose non-compliance. Braithwaite (2009) argues that individuals differ in their motivations to comply with tax law, and she identifies both positive (deference) and negative (or defiance) motivations. There are other approaches that emphasize social interactions (Cowell and Gordon, 1988; Gordon, 1989; Myles and Naylor, 1996; Kim, 2003; Fortin, Lacroix, and Villeval, 2007; Traxler, 2010). See Hashimzade, Myles, Tran-Nam (2013) for a survey of much of the theoretical literature. There are also several applied applications of social interactions. For example, Bloomquist (2011) incorporates social interactions in an agent-based model of taxpayer compliance, calibrates the model using data on human subjects' reporting behaviour in tax compliance laboratory experiments, and uses the model to investigate the behavioural foundations of observed reporting compliance from U.S. taxpayer random audits. Alm and McKee (2004) consider social interactions via a coordination game framework, and use laboratory experiments to test its predictions. Galbiati and Zanella (2012) develop an econometric model to isolate the social interaction effects on taxpayer compliance due to differences in audit coverage rates using tax agency audit data on Italian taxpayers.
} 
that it is via these social norms that peer effects seem likely to work, at least when information about peers is provided. ${ }^{5}$

There are numerous ways of introducing social norms in the compliance framework (Alm and Torgler, 2011). A simple way is to assume that there is a psychic cost, or a feeling of guilt, that is associated with evading one's own tax liability if one is not caught, as captured by the variable $\gamma$. This variable $\gamma$ measures in dollars how much the individual would pay to avoid the psychic loss associated with each dollar of unreported income. ${ }^{6}$ We posit that the greater is a society's social norm of compliance, the greater is the guilt that is felt by an individual who cheats on his or her tax liability. Note that the psychic cost arises only if one is cheating and is not caught cheating, as assumed and analyzed by Gneezy and Rustichini (2000). Thus, a taxpayer who complies fully experiences no change in utility from the psychic cost or guilt of evasion.

Putting these considerations together, equations (1) and (2) are modified as follows. The reporting decision becomes based upon:

$$
\text { Reporting Decision: } \quad E U=(1-p) U(I-t R-C-\gamma)+p U(I-t R-(1+f) t(I-R)-C)
$$

Similarly, the expected utility from non-filing involves calculation of:

$$
\text { Filing Decision: } \quad E U=\left(1-p^{*}\right) U(I-\gamma)+p^{*} U\left(I-\left(1+f^{*}\right) t I\right) \text {. }
$$

\footnotetext{
${ }^{5}$ In the literature on social norms, the "broken windows effect" (Wilson and Keeling 1982) is often encountered. Lefebvre et al. (2011) conduct a tax compliance laboratory experiment using university students in three European countries (Belgium, France, and the Netherlands) and two culturally distinct regions (Flanders and Wallonia). They find that "negative" information (e.g., reports of high levels of noncompliance) engenders a further decline in reporting compliance, but that "positive" information does not lead to improved compliance. The opposite conclusion is reported in a rare field study by Fellner, Sausgruber, and Traxler (2013), who find that, when households in communities believed to have high levels of noncompliance receive a letter informing them of high levels of compliance by their neighbours, a positive impact on compliance is observed.

${ }^{6}$ Note that we assume that there is no psychic benefit from paying the tax. This simplifies the analysis, and may be justified if one takes the "paying taxes is a duty" viewpoint. It is straightforward to introduce such a psychic benefit.
} 
As before, the individual must first choose whether or not to file a tax return, by comparing the value of expected utility from non-filing in equation (2)' with the expected utility of filing and reporting the optimal amount of income $R$ in equation (1)'; if the individual chooses to file, the optimal amount of $R$ is based on the solution to equation (1)'.

In the face of these many elements, the impacts on the individual's compliance decisions of variables like the tax rate and income reflect complicated interactions of income and substitution effects, and unambiguous comparative statics results often become elusive. Other variables are our focus here. For the audit and enforcement variables $\left(p, f, p^{*}, f^{*}\right)$, the comparative statics results are straightforward. For example, an increase in the enforcement rate for non-filing, $p^{*}$, increases the likelihood of filing a tax return. Also, an increase in the audit rate for filed returns $p$ increases the amount of reported income (conditional upon filing) but decreases the incentive to file a return for those who do not report fully. These latter results suggest one hypothesis:

Hypothesis 1: An increase in the audit rate for filers $p$ increases the amount of reported income of an individual who files a return. However, an increase in $p$ decreases the likelihood of filing a tax return for an individual who does not report fully.

Similarly, an increase in the cost of filing $C$ reduces the likelihood of filing but has no impact on reported income (conditional upon filing):

Hypothesis 2: An increase in the cost of filing $C$ decreases the likelihood filing a tax return, but has no impact on the amount of reported income of an individual who files a return.

Perhaps surprisingly, the impact of social norms on filing is not unambiguous, because $\gamma$ changes the psychic cost of cheating in both the reporting and the filing equations. ${ }^{8}$ However, it is

\footnotetext{
${ }^{7}$ Note that we assume that the psychic cost $\gamma$ is the same for non-filing and for underreporting. We do this mainly for simplicity. It is straightforward to allow for psychic costs that vary by type of non-compliance, and our results are unaffected. For discussion of the various ways in psychic costs have been introduced in evasion decisions, see again Hashimzade, Myles, and Tran-Nam (2013).

${ }^{8}$ More precisely, recall that an individual compares expected utility in the two cases (or equation (1)' versus equation (2)'). An increase in the psychic cost lowers expected utility in both bases, by an amount that depends upon the product of the enforcement probability and the marginal utility of income in the relevant state. In general, it is not possible to determine whether this change in expected utility is greater in one case versus the other.
} 
straightforward to demonstrate that an increase in $\gamma$ increases the level of reported income (conditional upon filing). This reasoning suggests several hypotheses on the effects of information:

Hypothesis 3: An increase in the psychic cost $\gamma$ has an ambiguous effect on the likelihood of an individual filing a tax return. However, an increase in $\gamma$ increases the amount of reported income of an individual who files a return.

Regardless, both the filing and the reporting decisions clearly depend upon the entire array of fiscal factors $\left(p, f, p^{*}, f^{*}, t, I, C, \gamma\right)$, as well as upon demographic variables that proxy for unobserved preferences. The next section presents our experimental framework for testing these hypotheses.

\section{Experimental design}

\section{General experimental features}

Our experimental setting implements the fundamental elements of the voluntary reporting systems of most country’s individual income tax. Participants earn income by performing a simple (computerized) task. They must choose whether or not to file a tax return; if they choose to file a return, they must purchase a tax form and must then choose how much income to report. Taxes are paid only on reported income. If an individual is audited, then any unreported taxes are discovered, and the individual must pay all unreported taxes plus a penalty. The enforcement rate for non-filing is set at zero, to reflect the fact that in most countries an individual who does not file faces little effective chance of detection. Subjects are fully and accurately informed about the various features of the experimental setting (e.g., tax rates, penalty rates, audit rates, tax form costs, and the like). This process is repeated over a number of rounds each representing a tax period. At the completion of the experiment, all participants are paid in cash their laboratory market earnings converted to U.S. dollars. 
Participants are recruited from the pool of undergraduate students and staff at a U.S. public university (Appalachian State University in Boone, NC) using the Online Recruiting System for Experimental Economics (ORSEE) developed by Greiner (2004). The participant database was built using announcements sent via email to all students and staff. Participants were invited to a session via email, and were permitted to participate in only one tax experiment, although other experimental projects are ongoing at the time and participants may have participated in other types of experiments. Only participants recruited specifically for a session were allowed to participate, and no participant had prior experience in this experimental setting. Methods adhere to all guidelines concerning the ethical treatment of human subjects. ${ }^{9}$

Upon arrival at the laboratory, participants are assigned to a computer station with each station being situated in an isolation carrel; they are also assigned to a specific group of 5 individuals, these groups are maintained throughout the session, and each group is assigned a single treatment for the duration of the experiment. The members of the group are considered one's "neighbours" in the experimental design. The dedicated experimental lab consists of 25 networked computers, a server, and software designed for this series of experiments. Basic instructions are provided via a hardcopy and also via a series of screen images. ${ }^{10}$ There is no interaction between the participants and the person running the experiment beyond the initial seating of the participants at terminals and the reading of the consent sheet. Decisions are made privately, and participants are not allowed to talk with one another during the session; participants also do not sign and return consent forms to further increase anonymity. Participants are informed that all responses are anonymous, that no individual identification will be collected,

\footnotetext{
${ }^{9}$ Note that the conversion rate of laboratory dollars to U.S. dollars varied by subject type. For student sessions, the conversion rate was 80 lab dollars to 1 U.S. dollar; for staff sessions, the conversion rate was 50 lab dollars to 1 U.S. The different conversion rates were designed to ensure that compensation was salient for students and for staff.

${ }^{10}$ All instructions for the various treatments, together with all computer screens, are available upon request.
} 
and that the only record of participation will be the receipt signed to receive payment at the end of the session. Participants are also told that payments will be made in private at the end of the session. Taken together, these experimental procedures effectively eliminate both subject-tosubject interaction and subject-to-experimenter interaction.

The detailed steps of the experiment can be briefly described. The earnings task requires the participants sort randomly arranged digits. The task is timed, with the fastest person in the group earning the highest payment and the slowest person earning the least payment. Individuals are informed of their earnings and those of other members of the group, without being able to identify specific individuals. Earnings range from 100 lab dollars and down in increments of 10 lab dollars.

Participants are then presented with a screen that provides the details of the treatment in effect. Here they are informed with certainty of the tax rate, the enforcement and the audit rates, and the enforcement and the penalty rates, as well as the details of the treatment policy intervention. The tax form is not yet provided, a feature that simulates the need for the participant to collect the information needed to file a return. Participants may choose to get a form or not, and there is a tax form cost $C$ (reflective of the overall costs of tax filing, including both time costs and financial costs). If the participant chooses not to obtain a tax form, then the participants does not file and is not subject to an audit in the current round, which reflects the typical feature of tax systems that individuals who do not file a return face a significantly lower (often zero) chance of audit. If the participant chooses to get the form, then the cost is deducted from the participant's income for the round. If the participant has obtained the form, then he or she may still choose to not file by selecting the "Not File" button on the tax form screen. Since the tax filing season is limited in the field, there is a time limit imposed ( 75 seconds) in the 
experiment, and a counter at the bottom of the tax form informs the participants of the time remaining. If the time expires and a tax form has not been filed, then the participant is automatically audited and an additional 10 percent penalty is imposed. Since the "Not File" button is always available, the timer simply imposes the requirement that a decision be recorded within the time limit.

If the participant chooses to file, then he or she must also choose the amount to report to the tax authority for each entry on the tax form (i.e., income and deduction). For each set of entries, the computer automatically calculates the resulting tax liability. Participants are able to experiment with different reports during the time allowed for filing, and they can observe the potential changes in their reported take home income.

The process of determining who among the filers is audited is generated by a computerized draw. After the return is filed, the participants are presented with an animated (computerized) representation of a bucket from which a draw is made. In this bucket there are 10 balls (either blue or white), with a white ball signifying no audit, a blue ball denoting an audit, and the number of blue balls relative to the number of white balls determining the audit rate. Each taxpayer is audited independently. The balls "bounce" in this bucket, and then a door opens and a ball exits the bucket through this door, with the color of the ball indicating whether the individual is audited. ${ }^{11}$ The audit applies only to the current period declarations, not to previous (or future) periods. The computer automatically deducts taxes paid and penalties (if any are owed) from participants' accounts. Participants choosing not to file a tax return are presented

\footnotetext{
${ }^{11}$ Many earlier laboratory studies (e.g., Alm, McClelland, and Schulze, 1991; Alm, Jackson, and McKee, 1992) utilized a single draw from a mechanical bingo cage for all individuals. The use of a mechanical bingo cage introduces several problems. First, a mechanical bingo cage may leave the subjects with the impression (even if mistaken) that only a fixed number of audits can occur within a round. Second, to make the draw from a mechanical bingo cage credible to subjects, the results of the draw must be announced; doing so means that the subjects learn if someone is audited, and this violates the precepts of a double blind design.
} 
with a screen that informs them that they will not be audited in the current round. After the audit process has been completed, the taxpayers are presented with a new screen that provides the earnings and audit outcome summary for the round.

As in the naturally occurring setting, various factors complicate the tax reporting decision in our experiments. In addition to reporting earned income, an individual can claim an allowed deduction (or a reduction in taxable income). We set the tax deduction at 15 percent of income. These deduction amounts are chosen such that the participants perceive them to be salient. We set the tax rate $t$ at 35 percent for all sessions. The penalty rate $f$ for audited returns is also fixed for all sessions at 50 percent (e.g., the participants must pay unpaid taxes plus a penalty of 50 percent of unpaid taxes if audited), a rate that is consistent with IRS policies; similarly, the enforcement penalty rate $f^{*}$ is fixed at 100 percent. The enforcement probability $p^{*}$ is set at zero. ${ }^{12}$ The audit probability $p$ for audited returns equals either 30 percent or 40 percent, and is varied once within the session; that is, the audit rate is set for the first 8 rounds, changes for the second 8 rounds, and reverts to the original level for the final 4 rounds. ${ }^{13}$ The tax form cost $C$ varies randomly within each session, from 0 to 2 lab dollars with an expected value of 1 .

\footnotetext{
${ }^{12}$ In the field, the actual audit probability for non-filers may not strictly be zero. However, we believe that there is substantial evidence that this non-filing audit rate is effectively very close to zero. For example, in the U.S. the IRS may conduct audits of suspected non-filers based on tips, on visible indicators of potential taxable income (e.g., reported mortgage interest payments or a filed business license), or through third-party reporting of unearned income, such as deposit interest. However, the frequency of non-filing audit is very low (Erard and Ho, 2001). In other countries, the frequency is essentially zero (Alm, Bahl, and Murray, 1991). Accordingly, we elect to implement for simplicity a zero audit probability in the lab setting. Note that our framework requires only that the probability of audit for non-filers be less than the probability of audit for filers.

${ }^{13}$ These rates are higher than official audit rates in the U.S. or elsewhere. However, the official IRS audit rate (currently under one percent) is somewhat of an understatement. The IRS conducts a range of audits, and for many types of audits the effective rates are quite high. Also, while overall official audit rates are quite low, among certain income and occupation classes they are more frequent. Finally, the IRS conducts a wide range of audit-type activities, including line matching and requests for information, and these activities are much more frequent. For example, in 2005 only 1.2 million individual returns of the 131 million individual returns filed were actually audited. However, in that year the IRS sent 3.1 million "math error notices" and received from third parties nearly 1.5 billion "information returns", which are used to verify items reported on individual income tax returns.
} 
Our experimental setting is very contextual, in order to provide the necessary degree of "parallelism" to the naturally occurring world that is crucial for the applicability of experimental results (Smith, 1982; Plott, 1987). Our experimental interface and instructions use tax language throughout, the participants decide whether or not to file a tax return, and they disclose tax liability in the same manner as on the typical tax form (e.g., entering income and deductions on a tax form). There is a time limit on the filing of income, and the individual is automatically audited if he or she fails to file on time.

Participants are not told the exact duration of the experimental session, which is predetermined to last for 20 real rounds. Including instructions, three practice rounds, and the 20 real rounds, sessions take on average 70 minutes to complete. In all 212 subjects participated in these sessions. Earnings averaged $\$ 18$ for student subjects. Staff participants received a higher exchange rate to reflect their higher outside earnings, and average payoffs for staff were $\$ 28$. At the end of the session, the participants completed a short questionnaire in which they report their age, gender, and whether they prepare and file their own taxes (a measure of their direct experience with the tax system).

\section{Experimental treatments}

Recall that our objective is to examine the effects of information about the compliance behaviour of one's peers on an individual's own choices, because information on the filing and reporting behaviour of one's neighbours allows an individual to infer the social norm of compliance. The coefficient $\gamma$ in equations (1)' and (2)' captures a wide range of psychic costs associated with either incorrect reporting of tax liabilities or failing to file a tax return. We focus on one of the elements of such psychic costs, or the extent to which the individual's behaviour deviates from the group's social norm. We do this by conducting treatments sessions in which 
different types of information about the compliance behaviours of other participants are provided. Table 1 summarizes these experimental treatments.

To establish a baseline, Treatment 1 (T1) provides no information of any kind about other “neighbour" individuals, where one's neighbours are the members of the group to which the subjects are assigned for all rounds of the experiment and where each group is assigned a single treatment for the duration of the experiment. In three other treatments (T2, T3, and T4), some information is provided. In the treatments where neighbour information is provided, it is presented after the audit process. For example, in T2, after all persons have made their filing decision, the computer informs all members of a group of the percent of the other group members who filed taxes in the current round; this information only reports the percent of one's neighbours who submitted a tax return, not the amounts reported, and it can contain information on compliance behaviour that indicates either more or less compliance, depending on the actual

percent that is conveyed. Similarly, in T3 all members of the group are informed of the results of the audits (if any) for the current round; that is, each individual is told the amount (in tokens) of unpaid taxes plus fines paid by the other members of the group who are audited, information that provides another positive or negative measure of tax reporting behaviour of one's neighbours. In T4 both types of information are provided. Note again that the members of the group are maintained throughout the experiment and that each group is assigned a single treatment for the duration of the experiment, so that there is opportunity to learn the group behaviour over time.

\section{Expected value calculations}

A risk-neutral individual uninfluenced by psychic costs will make his or her choices so as to maximize the expected value of the compliance gamble. Accordingly, it is useful to calculate 
the expected value in the treatments; these calculations also provide support for the hypotheses from the earlier discussion.

For example, in the baseline session (T1), the expected value from filing a tax return $E V($ Filing $)$ equals $[(1-p)(I-t R-C)+p(I-t R-(1+f) t(I-R)-C)]$, where $p$ is the probability that a tax return is selected for audit, $t$ is the tax rate on reported income, $f$ is the penalty rate on undeclared taxes, $I$ is the individual's "true" income, $R$ is the amount of reported income net of any allowable tax deductions, and $C$ is the tax form cost. When $p=0.3, t=0.35, f=0.5, C=0$, and the allowable tax deduction is 15 percent of "true" income, then $E V($ Filing) equals 65 for $I=100$ when the individual reports fully and honestly. In contrast, the expected value from non-filing $E V\left(\right.$ Non-filing) equals $\left[\left(1-p^{*}\right) I+p^{*}\left(I-\left(1+f^{*}\right) t I\right)\right]$, where $p^{*}$ is the enforcement rate (or the probability that an individual who has not filed a return is apprehended by an audit) and $f^{*}$ is the enforcement penalty. Given parameter values (mainly $p^{*=0}$ ), the expected value from non-filing equals 100. In general, there is no incentive for an individual to file in the baseline (T1) session, even for different levels of reported income (including 0).

Changes in the parameters affect these expected values in standard ways. For example, an increase in the cost of filing $C$ reduces expected value for an individual who files, and so reduces the likelihood that an individual will file a tax return. Similarly, an increase in the audit rate for filers $p$ reduces the expected value of filing for an individual who has not reported fully (while leaving unchanged the expected value of non-filing), and so reduces the likelihood that the individual will file a tax return.

The other sessions (T2, T3, and T4) introduce information about the filing and reporting compliance of group members, information that is expected to affect behaviour by changing the psychic cost of cheating $\gamma$. In general, an increase in $\gamma$ reduces both the expected value from 
filing and from non-filing by equal amounts; given that EV(Filing) generally remains less than $E V$ (Non-filing) (even if the difference becomes smaller when $\gamma$ increases), a change in the psychic cost reduces but does not eliminate the incentive for an individual. Even so, for an individual who has chosen to file a tax return, an increase in the psychic cost increases the amount of reported income.

Overall, these expected value calculations indicate that the optimal individual strategy for a risk-neutral individual is not to file a tax return. More generally, optimal individual decisions for any linear payoff function will tend to exhibit all-or-none behaviour. Only very large changes in parameter values alter this tendency toward all-or-none behaviour.

\section{Results}

The student portion of the subject pool covered a broad range of years in studies and majors, and no single major exceeded 8 percent of the pool. The staff pool was similarly diverse covering all levels of support staff, non-academic professional staff, and faculty. Overall, 43 percent of the participants were male, the average age was 27 years, and students were 72 percent of the subject pool. We pool our subjects for the data analysis, as justified by the results reported in Alm, Bloomquist, and McKee (2015).

We begin by presenting aggregate results (Table 2) along with some summary statistics. Our focus is on two different aspects of compliance: the Filing Rate (defined as the proportion of all observations in a treatment in which the subject chose to file a tax form), and the Reporting Rate (defined as the average across observations in a treatment of [Taxes Paid/Taxes Owed]). Note that the average filing and reporting rates are relatively low, at least compared to estimates for individuals subject to information returns and employer withholding. However, these 
compliance rates are comparable to observed rates for income not subject to information returns and/or employer withholding. ${ }^{14}$

Some treatment effects are immediately apparent in the aggregate statistics. Informing subjects of the percent of one's neighbours who file lowers both filing and reporting rates (comparing $\mathrm{T} 2$ with $\mathrm{T} 1$ ); the differences in the filing and the reporting rates are statistically significant in these treatments at the 1 percent level. However, informing subjects of the results of audits (or the amounts of unpaid taxes plus penalties of other group members) increases both filing and reporting (T3 versus T1); these differences are also significantly different. Combining both information types (T4) yields significantly lower filing and reporting rates relative to the baseline (T1), although both filing and reporting rates in T4 are higher than in T2 (where subjects are not given any audit results information). The simple conclusion one might draw here

\begin{tabular}{|c|c|}
\hline \\
\hline \multicolumn{2}{|c|}{$\begin{array}{l}{ }^{4} \text { For example, the IRS has established through its audits the "Net Misreporting Percentage" (NMP) for d } \\
\text { sources of income, which measures unreported (or "misreported") income as a fraction of the absolute val } \\
\text { "true" income. (If unreported income equals } \$ 20 \text { and reported income equals } \$ 80 \text {, then the NMP equals } \\
\text { N20/[[\$20+\$80|]), or } 20 \text { percent. Alternatively, if unreported income is } \$ 20 \text { and reported income is }-\$ 80, \\
\text { NMP equals }(\$ 20 /[|\$ 20-\$ 80|]) \text {, or } 33.3 \text { percent.) As indicated in the table below for } 2001 \text {, the IRS (2006) } \\
\text { estimated that the NMPs are lowest for income types that are matched with third-party matching informat } \\
\text { and employer withholding and highest for little or no reporting/nonwitheld income types. The NMP for } \\
\text { ncome (which is subject both information returns and employer withholding) is virtually zero, at } 1 \text { percer } \\
\text { contrast, the NMP for income not subject to third-party matching or employer withholding (e.g., nonfarm } \\
\text { income, farm income, other gains, and rent and royalties) is } 54 \text { percent. } \\
\qquad \text { Source of Income }\end{array}$} \\
\hline $\begin{array}{l}\text { Substantial Information Reporting and } \\
\text { Withholding (e.g., wage income) }\end{array}$ & 1 \\
\hline $\begin{array}{l}\text { Substantial Information Reporting (e.g., } \\
\text { interest income) }\end{array}$ & 5 \\
\hline $\begin{array}{l}\text { Some Information Reporting (e.g., capital } \\
\text { gains) }\end{array}$ & 9 \\
\hline $\begin{array}{l}\text { Little or No Information Reporting (e.g., } \\
\text { non-farm proprietor income) }\end{array}$ & 54 \\
\hline
\end{tabular}

Updated IRS estimates for the 2006 tax gap (IRS, 2012) depict a largely similar pattern across broader categories. Similar patterns are also suggested by IRS data on deductions. As discussed by Alm and Soled (2013), preliminary IRS data demonstrate that taxpayers routinely mischaracterize their automobile depreciation and operating expenses, largely because these expenses are not subject to information returns and employer withholding. IRS estimates of the NMP for automobile and truck expenses on Schedules C and F and Form 2106, averaged on an annual basis for the three tax years 2006, 2007, and 2008, indicate that taxpayer mischaracterizations occur on a massive scale. On Schedule C, the overall NMP is 33 percent; similarly, the NMP for Schedule F reports is 35 percent, and the NMP for Form 2106 reports actually exceeds 100 percent. This misreporting of automobile expenses is common and significant across all income classes. 
is that the focus of individuals is on the behaviour of the enforcement agency (e.g., via audit results) rather than on their neighbours (e.g., via filing behaviour).

However, these simple means focus on the aggregate, or average, behaviour, and they do not control for other factors such as individual subject effects and interaction effects. Such an emphasis on aggregate behaviour can hide substantial variation in individual behaviour. Also, the cross-treatment comparisons reflect mainly the dummy variables (or the treatment) effects and not the contribution of the levels of the information (or the actual percent of subjects who actually file and the actual reporting behaviour of filers). Finally, as shown in our theory section, information on one's neighbours can lead to higher or lower filing and reporting compliance; that is, the social norm that emerges may be one in which filing (or reporting) is higher or lower than the level absent the information on neighbour behaviour. The theory also implies only a convergence of behaviour arising from social norms, not the resulting equilibrium level of compliance, and a group or neighbourhood may focus either on a low-compliance or on a highcompliance equilibrium (Alm and McKee, 2004; Bloomquist, 2011). Thus, it is also necessary to condition the analysis by controlling for lagged behaviour.

We address these various issues, and also test the strength of the initial impressions from the aggregate data, by estimating econometric models that permit conditional estimations of the treatment effects at the individual level while holding other factors constant and also by examining more closely the heterogeneity in individual behaviour.

Starting with econometric models, we estimate the following empirical model:

$$
Y_{\mathrm{i}, \mathrm{t}}=\beta_{1}+\beta_{2} I_{\mathrm{i}, \mathrm{t}}+\beta_{3} W_{\mathrm{i}, \mathrm{t}}+\beta_{4} p_{\mathrm{i}, \mathrm{t}}+\beta_{5} C_{\mathrm{i}, \mathrm{t}}+\beta_{6} \text { Treatment }_{\mathrm{t}}+\beta_{7} X_{\mathrm{i}}+\psi_{\mathrm{t}}+u_{\mathrm{i}}+\varepsilon_{\mathrm{i}, \mathrm{t}}
$$


where the dependent variable $Y_{\mathrm{i}, \mathrm{t}}$ denotes subject $i$ 's filing or reporting decision in period $t$; $I_{\mathrm{i}, \mathrm{t}}$ is subject $i$ 's earned income in period $t ; W_{\mathrm{i}, \mathrm{t}}$ is subject $i$ 's accumulated income over previous rounds (or "wealth") in period $t ; p_{\mathrm{i}, \mathrm{t}}$ is the audit probability for subject $i$ in period $\mathrm{t}$; $C_{\mathrm{i}, \mathrm{t}}$ is the cost that subject $i$ must pay to obtain a tax form in period $t$; Treatment $_{\mathrm{t}}$ denotes the vector of treatment variables (or the type of information that is provided about the tax filing and audit experience of one's neighbours), as discussed below; $X_{\mathrm{i}}$ is a vector of demographic variables (e.g., subject age and sex); $\psi_{\mathrm{t}}$ is a set of $T-1$ dummies that capture potential non-linear period effects; $u_{\mathrm{i}}$ are random effects that control for unobservable individual characteristics ${ }^{15} ; \varepsilon_{\mathrm{i}, \mathrm{t}}$ is the contemporaneous additive error term; and $\beta_{k}$ is the coefficient for variable $k$.

From this basic specification in equation (3), we estimate models for each decision undertaken by the subjects: filing a tax form Filing Rate ( $Y_{\mathrm{i}, \mathrm{t}}$ equals 1 if the form is filed and 0 otherwise); and, for individuals who file a form, their Reporting Rate ( $Y_{\mathrm{i}, \mathrm{t}}$ equals [Taxes Paid/Taxes Owed]). Our unit of analysis is the individual subject. Since we have repeated observations (20 periods) on decisions made by individual subjects, our data set is a panel. For each of the decision variables, we estimate equation (3) using GLS panel methods with subject random effects. ${ }^{16}$ The Filing Rate equation is estimated using a linear probability model for all individuals; the Reporting Rate equation is estimated without restrictions (i.e., with no adjustment for censoring because the reporting value is naturally bounded at zero and one) using data from only those individuals who filed a return. Estimation results are presented in Table 3.

For both behavioural estimations, we include control variables (Age, Gender, Income, and Wealth), and in the estimation of filing behaviour we also include a dummy variable to reflect whether the subject has in the past prepared his or her own actual individual income tax

\footnotetext{
${ }^{15}$ Given the between subject design of key treatment variables, we must utilize a random effects specification to control for subject heterogeneity. See Wooldridge (2002).

${ }^{16}$ The GLS estimation incorporates clustered standard errors.
} 
return (Prepare Own Taxes Dummy) in order to control for the effect of field experience on behaviour in the laboratory. We also include Lag Own Audited Dummy (a dummy variable equal to 1 if the individual is audited in the previous period and 0 otherwise) to capture the effect of the individual's experiences with the audit process.

We enter our treatment variables in two forms, as simple dummy variables and also as variables with more specific informational content. . The Neighbour Filing Information Dummy equals 1 if neighbour filing information is revealed (i.e., all observations for T2) and 0 otherwise. Similarly, the Neighbour Audit Information Dummy equals 1 if information on neighbour audit results is revealed (i.e., all observations for T3) and 0 otherwise. The levels of the neighbour behaviour are expected to be important, since the theoretical predictions concerning the overall effect of the information are ambiguous (i.e., the possibility of coordinating on the low or high filing/reporting equilibrium). We include lagged (one period) variables for these levels: Lag Neighbour Filing Percent Information (equal to the percent of other group members who filed a return in the previous period); and Lag Neighbour Audit Results Information (equal to the sum of unpaid taxes and penalties paid by other group members who are audited in the previous period) ${ }^{17}$

It should be noted that we have estimated many alternative specifications to explore the robustness of our main results. We have included interaction terms between the treatment dummy variables, and also between the treatment dummy variables and the individuals own (lagged) behaviour. We have estimated a standard logit specification for the Filing Rate equation, rather than the linear probability model. We have estimated a standard selection model

\footnotetext{
${ }^{17}$ We have investigated longer lags. However, the decay factor for neighbour information is very high, and the coefficients on longer lags ( 2 and 3 periods) were never significant.
} 
for the individual's decisions, given that reporting is conditional upon filing. ${ }^{18}$ We have also examined specifications with different combinations of explanatory variables. For the most part, our results are unaffected, and so we focus on the results in Table 3.

These conditional estimates clarify many of our initial impressions, and generally support our three main hypotheses. These results show that, after controlling for the dynamic effect of neighbour behaviour, the behaviour of one's neighbours has a statistically significant and economically large impact on filing and reporting behaviour, as suggested by Hypothesis 3 . For the Filing Rate decision, the coefficient on Lag Neighbour Filing Percent Information is positive and significant, indicating that an individual is more likely to file a return when the proportion of neighbours filing is greater. However, the treatment dummy variable (Neighbour Filing Information Dummy) has a negative and significant coefficient for Filing Rate, indicating that simply having this information decreases filing, a result that is consistent with the aggregate results reported in Table 2 .

For the Reporting Rate decision, the coefficient on Lag Neighbour Audit Results Information has a positive and significant impact on individual compliance rates, indicating a positive impact of peer effects on the reporting decision when this information is provided. The coefficient on the treatment dummy (Neighbour Audit Information Dummy) is negative but insignificant. Again, the overall effects show that the mere presence of the information does not necessarily have a positive effect on either filing or reporting, but rather that the levels of behaviour complement the filing and reporting behaviour.

\footnotetext{
${ }^{18}$ As noted, we estimate the Reporting Rate equation using only data from the participants who file a form. These estimates might be influenced by selection bias, since the reporting decision is conditional upon the prior filing decision. We have estimated a standard two-step Heckman procedure that attempts to control for selection, in which the inverse Mills ratio from the first stage Filing Rate equation is included in the second stage Reporting Rate equation. However, this two-step procedure does not appear to provide robust estimates because identification arises from the nonlinearities associated with the normality assumption.
} 
These estimation results in Table 3 indicate that simply making publicly available information regarding neighbour filing and tax reporting behaviour lowers the propensity to file and has no effect on tax reporting behaviour. Thus, a policy of making this information public would appear to be ineffective at best and potentially harmful to the tax agency. However, when informed of the actual prior behaviour of their neighbours, the participants in the experiment respond by coordinating on the social norm of compliance, as indicated by the positive coefficient on measure of our levels.

Thus, information about peer effects has complicated and subtle impacts. These results clearly indicate that peer effects matter; that is, knowing about how one's neighbours are - or are not - complying with the tax laws changes one's own behaviour, even if in perhaps unintended ways. ${ }^{19}$ Since the taxpayers in the experimental setting adjust their behaviour toward the social norm, the key for the tax agency is the establishment of a compliance social norm.

Other results provide some support for the Hypotheses 1 and 2. An increase in the Audit Probability for filers $(p)$ has a positive and significant effect on reporting, but has no significant effect on filing behaviour; this latter result suggests that non-filers are not motivated by the desire to avoid the audit process. An individual who was previously audited (Lag Own Audited Dummy) is more likely to report more taxes. These results are consistent with Hypothesis 1. Filing is negatively correlated with the cost of obtaining the tax forms (Cost of Form), as suggested by Hypothesis 2 .

The signs on the control variable coefficients are generally consistent with results reported in the literature (Alm, Jackson, and McKee, 1992). Filing and reporting rates are lower

\footnotetext{
${ }^{19}$ Alm, Jackson, and McKee (2009) also find that the information dissemination of audit results often has complicated effects on taxpayer compliance. See also Kastlunger et al. (2009).
} 
for men than for women, and are negatively correlated with wealth. Filing is increasing in income, but compliance is not significantly correlated with income.

It is also important to examine whether behavioural responses exhibit significant heterogeneity. For example, there may be heterogeneity by subject type (e.g., students versus non-students). It is also possible that an individual may alter his or her filing/non-filing behaviour over time within a session. Such behaviour may be risky in the field since an individual is "in the system" once he or she has filed a tax return, so that the individual may believe (whether true of not) that not filing in the future after filing in the past would lead to an audit. However, in our experimental setting where all audit selection is random, such conditional filing behaviour may be present. Further, such behaviour may also reflect the possibility that an individual's response to information about neighbour behaviour depends upon the individual's own previous behaviour, such as whether the individual submitted a return in the previous round. ${ }^{20}$

We find no significant difference in the behavioural responses of students versus nonstudents, a result that has been found in other tax compliance experiments, and so we do not include a control variable for subject type in our final reported estimations. ${ }^{21}$

We also find little evidence of individual behavioural response heterogeneity over rounds of the experiment. Rather, we find considerable support for behavioural stability, at least after

\footnotetext{
${ }^{20} \mathrm{We}$ are grateful to the Editor and an anonymous referee for the suggestion that we explore this response heterogeneity. For example, we have estimated a specification for the filing equation in which we interacted the treatment dummy variable with the individual's own lagged filing decision, and a similar specification (using the individual's penalty payments) for the reporting equation. These specifications were estimated to examine whether an individual's response to information about neighbour behaviour depends on whether the individual submitted a return in the previous round (for the filing decision) or upon the extent to which the individual evaded taxes (for the reporting decision).

${ }^{21}$ See Alm, Bloomquist, and McKee (2015) for a detailed analysis of these subject pool effects in tax compliance experiments. See Ball and Cech (1996) for a more general analysis of subject pool effects in other experimental settings.
} 
some initial learning; that is, we find that individuals tend to exhibit what might be termed "habit persistence".

For example, if we focus on the baseline setting (T1), we find that 19 of the 40 subjects filed 17 periods or more (out of 20 periods) and 8 subjects filed 5 periods or fewer. Thus, less than half of the subjects engaged in "high" levels of switching behaviour.

The estimation results in Table 3 also suggest that subject behavior exhibits considerable habit persistence. These results indicate that individuals change their filing behaviour in response to information regarding the behaviour of their neighbours, but that they do not change their filing decision in response to whether they were previously audited (with a one-period lag).

Finally, we consider habit persistence in the larger dataset with all treatments. In Table 4, we estimate the individual's Filing Rate as a function of various lags on the dependent variable, using GLS panel methods with subject random effects, clustered standard errors, and a linear probability model. As with the estimation results in Table 3, we see that the coefficients on all lagged behaviours are statistically significant, suggesting strongly the presence of habit persistence behaviour. It appears that little switching is going on, thereby providing further assurances that our findings related to changes in individual behaviour in response to shared information on group filing and reporting are not the result of chance occurrence. See also Figure 1, which plots by round the average of each individual's Filing Rate, averaged across all treatments and all subjects. The average filing rate is highest in round 1 (69 percent), with the rate falling quickly to around 60 percent by round 5 and with the last 5 rounds exhibiting very stable behaviour. Overall, the average Filing Rate falls in the narrow range of 0.58 and 0.68 .

This behavioural stability is consistent with an individual who reacts to the behaviour of one's neighbours, and who eventually converges to a durable pattern of behaviour. If a social 
norm of honest reporting by the group eventually emerges, and if the individual receives information about this group behaviour, then we would expect little variability in individual behaviour as everyone sees and reacts to the same signals; a similar pattern of behaviour would emerge for a social norm of dishonest reporting. In fact, this behaviour is what we see. Such behaviour suggests strong habit persistence, which is consistent with social norms emerging and affecting behavior but eventually creating stability and durability. ${ }^{22}$ We have also investigated this pattern of behaviour for tax reporting, and we again find similar results.

\section{Conclusions}

Many factors affect an individual's compliance decisions. Our experimental results show that one important factor is information about the behaviour of one's peers: individuals are influenced by what their "neighbours" choose to do, at least when this information is provided, even if the precise ways in which this information matters is not always clear-cut. Specifically, we find that providing information on what one's neighbours are doing has a statistically significant and economically large impact on individual filing and subsequent reporting decisions. However, this "neighbour” information does not always improve compliance, depending on the precise way in which this information is provided.

More broadly, our results indicate that strategies to improve compliance must be based on more than enhanced enforcement effort, even though our results clearly show that enforcement (e.g., audits and penalties) have predictable effects on compliance. Instead, what is needed is a multi-faceted policy approach that emphasizes enforcement (or a "punishment paradigm" for the tax administration), but one that also enhances cooperative social norms. In this regard, our

\footnotetext{
${ }^{22}$ Cummings et al. (2009) find similar behaviour for the tax compliance experiments that they conducted in various African countries.
} 
results are consistent with another tax administration paradigm, what might be termed a "trust paradigm", in which individual views on the reliability of the tax authorities - their "trust" in the ethical behaviour of authorities - affects their own individual behaviour. Our results are also consistent with a "service paradigm" for tax administration, in which taxpayers are more likely to respond positively to a tax administration that no longer views them simply as potential criminals and that instead acts as a facilitator and as a provider of services to taxpayer-citizens. Both of these latter paradigms are broadly consistent with the role of social norms on the compliance decision. It is clear from our research here, and from many other contributions to the evasion literature as discussed throughout, that social norms are operational and that they can be exploited to enhance tax reporting and filing. A wide range of policies, reflecting and appealing to the equally wide range of motivations that lie behind individuals' compliance decisions, is necessary for enhancing tax compliance. ${ }^{23}$

\section{References}

Akerlof, G. A. and Kranton, R. E. (2000), 'Economics and identity', The Quarterly Journal of Economics, vol. 115 (no. 3), pp. 715-753.

Allingham, M. and Sandmo, A. (1972), 'Income tax evasion: A theoretical analysis', Journal of Public Economics, vol. 1 (no. 3-4), pp. 323-338.

Alm, J. (1999), 'Tax compliance and administration', in W. B. Hildreth and J. A. Richardson (eds.), Handbook on Taxation, New York, NY: Marcel Dekker, Inc., pp. 741-768.

Alm, J. (2012), 'Measuring, explaining, and controlling tax evasion: Lessons from theory, experiments, and field studies', International Tax and Public Finance, vol. 19 (no. 1), pp. 54-77.

Alm, J., Bahl, R., and Murray, M. N. (1991), 'Tax base erosion in developing countries', Economic Development and Cultural Change, vol. 39 (no. 4), pp. 849-872.

\footnotetext{
${ }^{23}$ See Alm and Torgler (2011) for a more detailed discussion of these paradigms. Note that the "trust paradigm" is reflected in a range of slightly different but clearly related administrative approaches, with roots in the psychology of taxation (Lewis, 1982; Kirchler, 2007), such as the "slippery slope" framework of Kirchler, Hoelzl, and Wahl (2008) and Muehlbacher, Kirchler, and Schwarzenberger (2011), the "committed" versus "capitulative" versus "creative" compliance framework of McBarnet (2004), and the "deference" versus "defiance" motives of Braithwaite (2009). Enforcement actions should be tailored to reflect these many different motivations.
} 
Alm, J., Bloomquist, K. M., and McKee, M. (2015), 'The external validity of tax compliance experiments,' Economic Inquiry, vol. 53 (4), 1170-1186.

Alm, J., Cherry, T., Jones, M., and McKee, M. (2010), 'Taxpayer information assistance services and tax reporting behaviour', Journal of Economic Psychology, vol. 31 (no. 4), pp. 577586.

Alm, J., Jackson, B. R., and McKee, M. (1992), 'Estimating the determinants of taxpayer compliance with experimental data', National Tax Journal, vol. 65 (no. 1), pp. 107-114.

Alm, J., Jackson, B. R., and McKee, M. (2009), 'Getting the word out: Increased enforcement, audit information dissemination, and compliance behaviour', Journal of Public Economics, vol. 93 (no. 3-4), pp. 392-402.

Alm, J., and McKee, M. (2004), 'Tax compliance as a coordination game', Journal of Economic Behaviour and Organization, vol. 54 (no. 3), pp. 297-312.

Alm, J., and Soled, J. A. (2013), 'The Internal Revenue Code and Automobiles: A Case Study of Taxpayer Noncompliance', Florida Tax Review, vol. 14 (no. 10), pp. 419-458.

Alm, J., and Torgler, B. (2011), 'Do ethics matter? Tax compliance and morality', Journal of Business Ethics, vol. 101 (no. 4), pp. 635-651.

Andreoni, J., Erard, B., and Feinstein, J. S. (1998), 'Tax compliance', The Journal of Economic Literature, vol. 36 (no. 2), pp. 818-860.

Asch, S. E. (1951), 'Effects of group pressure upon the modification and distortion of judgments', in H. S. Guetzkow (ed.), Groups, Leadership, and Men-Research in Human Relations, Pittsburgh, PA: Carnegie Press, pp. 177-190.

Asch, S. E. (1952), Social Psychology, Englewood Cliffs, NJ: Prentice-Hall, Inc.

Ball, S. B. and Cech, P.-A. (1996), 'Subject pool choice and treatment effects in economic laboratory research', Research in Experimental Economics, vol. 60 (no. 2), pp. 239-292.

Becker, G. S. (1968), 'Crime and punishment - An economic approach', The Journal of Political Economy, vol. 76 (no. 2), pp. 169-217.

Bloomquist, K. M. (2011), 'Tax compliance as an evolutionary coordination game: An agentbased approach', Public Finance Review, vol. 39 (no. 1), pp. 25-49.

Braithwaite, V. (2009), Defiance in Taxation and Governance - Resisting and Dismissing Authority in a Democracy, Cheltenham, UK and Northhampton, MA: Edward Elgar Publishing.

Cowell, F. (1990), Cheating the Government: The Economics of Evasion, Cambridge, MA: The MIT Press.

Cowell, F. A. and Gordon, J. P. F. (1988), 'Unwillingness to pay', Journal of Public Economics, vol. 36 (no. 3), pp. 305-321.

Cummings, R.G., Martinez-Vazquez, J., McKee, M., and Torgler, B. (2009), 'Tax Morale Affects Tax Compliance: Evidence from Surveys and an Artefactual Field Experiment,' Journal of Economic Behavior and Organization, vol. 70, pp. 447-457.

Dawes, R. M. (1980), 'Social dilemmas', Annual Review of Psychology, vol. 31 (no. 2), pp. 169193.

Elster, J. (1989), The Cement of Society - A Study of Social Order, Cambridge, UK: Cambridge University Press.

Elster, J. (1999), Alchemies of the Mind, Cambridge, UK: Cambridge University Press.

Erard, B. and Ho, C.-C. (2001), 'Searching for ghosts: Who are the non-filers and how much tax do they owe?', Journal of Public Economics, vol. 81 (no. 1), pp. 25-50. 
Fellner, G., Sausgruber, R., and Traxler, C. (2013), 'Testing enforcement strategies in the field: Threat, moral appeal, and social information', Journal of the European Economic Association, vol. 11 (no. 3), pp. 634-660.

Frey, B. (1997), Not Just For the Money - An Economic Theory of Personal Motivation, Cheltenham, United Kingdom: Edward Elgar Publishing Limited.

Fortin, B., Lacroix, G., and Villeval, M.-C. (2007), 'Tax evasion and social interactions', Journal of Public Economics, vol. 91 (no. 11-12), pp. 2089-2112.

Galbiati, R. and Zanella, G. (2012), 'The tax evasion social multiplier: Evidence from Italy', Journal of Public Economics, vol. 96 (no. 5-6), pp. 485-494.

Gordon, J. P. F. (1989), 'Individual morality and reputation costs as deterrents to tax evasion', European Economic Review, vol. 33 (no. 4), pp. 797-805.

Gneezy, U. and Rustichini, A. (2000), 'A fine is a price', Journal of Legal Studies, vol. 29 (no. 1, Part 1), pp. 1-18.

Greiner, B. (2004), 'The online recruitment system ORSEE 2.0 - A guide for the organization of experiments in economics', Department of Economics Working Paper Series in Economics 10, University of Cologne, Cologne, Italy.

Hashimzade, N., Myles, G. D., and Tran-Nam, B. (2013), 'Applictions of Behavioural Economics to tax evasion”, Journal of Economic Surveys, vol. 27 (no. 5), pp. 941-977.

Internal Revenue Service (2006), Tax Year 2001 Federal Tax Gap (Extended Version), Washington, D. C.: IRS Office of Research, Analysis, and Statistics.

Internal Revenue Service (2012), Federal Tax Compliance Research: Tax Year 2006 Tax Gap Estimation, Washington, , D. C.: IRS Office of Research, Analysis, and Statistics.

Kastlunger, B., Kirchler, E., Mittone, L., and Pitters, J. (2009), 'Sequences of audits, tax compliance, and taxpaying strategies', Journal of Economic Psychology, vol. 30 (no. 4), pp. 405-418.

Kelman, H. C. (1958), 'Compliance, identification, and internalization: Three processes of attitude change', Journal of Conflict Resolution, vol. 2 (no. 1), pop. 51-60.

Kim, Y. (2003), 'Income distribution and equilibrium multiplicity in a stigma-based model of tax evasion', Journal of Public Economics, vol. 87 (no. 9), pp. 1591-1616.

Kleven, H. J., Knudsen, M. B., Kreiner, K. T., Pedersen, S., and Saez, E. (2011), 'Unwilling or unable to cheat? Evidence from a randomized tax audit experiment in Denmark', Econometrica, vol. 79 (no. 3), pp. 651-692.

Kirchler, E. (2007), The Economic Psychology of Tax Behaviour, Cambridge, UK: Cambridge University Press.

Kirchler, E., Hoelzl, E., and Wahl, I. (2008), 'Enforced versus voluntary tax compliance: The 'slippery slope' framework', Journal of Economic Psychology, vol. 29 (no. 2), pp. 210225.

Lefebvre, M., Pestieau, P., Reidl, A., and Villeval, M. (2011), 'Tax evasion, welfare fraud, and 'the broken windows' effect: An experiment in Belgium, France and the Netherlands', CESifo Working Paper No. 3408, Center for Economic Studies Ifo Institute, Munich, Germany.

Lewis, A. (1982), The Psychology of Taxation, Oxford, UK: Martin Robertson Publishers.

McBarnet, D. (2004), Crime, Compliance, and Control, Burlington, VT: Ashgate/Dartmouth Publishers Ltd.

Milgram, S. (1974), Obedience to Authority: An Experimental View, New York, NY: Harper Row Publishing. 
Muehlbacher, S., Kirchler, E., and Schwarzenberger, H. (2011), 'Voluntary versus enforced tax compliance: Empirical evidence for the 'slippery slope' framework', European Journal of Law and Economics, vol. 32 (no. 1), pp. 89-97.

Myles, G. D. and Naylor, R. A. (1996), 'A model of tax evasion with group conformity and social customs', European Journal of Political Economy, vol. 12 (no. 1), pp. 49-66.

Orviska, M. and Hudson, J. (2002), 'Tax evasion, civic duty and the law abiding citizen', European Journal of Political Economy, vol. 19 (no. 1), pp. 83-102.

Plott, C. R. (1987), 'Dimensions of parallelism: Some policy applications of experimental methods', in A. E. Roth (ed.), Laboratory Experimentation in Economics: Six Points of View, New York, NY: Cambridge University Press, pp. 193-229.

Putnam, R. D. (2000), Bowling Alone: The Collapse and Revival of American Community, New York, NY: Simon \& Schuster Publishing.

Sandmo, A. (2005), 'The theory of tax evasion: A retrospective view', National Tax Journal, vol. 58 (no. 4), pp. 643-663.

Sandmo, A. (2012), 'An evasive topic: Theorizing about the hidden economy', International Tax and Public Finance, vol. 19 (no. 1), pp. 5-24.

Schmölders, G. (1960), Das Irrationale in der Offentlichen Finanzwirtschaft [The Irrational in Public Finance], Frankfurt am Main, Germany: Suhrkamp.

Sherif, M. (1936), The Psychology of Social Norms, New York, NY: Harper Collins Publishing.

Slemrod, J. and Yitzhaki, S. (2002), 'Tax avoidance, evasion, and administration', in A. J. Auerbach and M. Feldstein (eds.), Handbook of Public Economics, Amsterdam, London, and New York: Elsevier North-Holland, pp. 1423-1470.

Smith, V. (1982), 'Microeconomic systems as an experimental science', The American Economic Review, vol. 72 (no. 5), pp. 923-955.

Torgler, B. (2007), Tax Compliance and Tax Morale: A Theoretical and Empirical Analysis, Cheltenham, UK: Edward Elgar Publishing.

Traxler, C. (2010), 'Social norms and conditional cooperative taxpayers', European Journal of Political Economy, vol. 26 (no. 1), pp. 89-103.

Wasserman, S. and Faust, K. (1994), Social Network Analysis: Methods and Applications, Cambridge, UK: Cambridge University Press.

Wilson, J. Q. and Kelling, G. L. (1982), 'Broken windows: The police and neighbourhood safety', The Atlantic Monthly, vol. 249 (no. 3), pp. 29-38.

Wooldridge, J. M. (2002), Econometric Analysis of Cross Section and Panel Data, Cambridge, MA: The MIT Press.

Young, H. P. (1998), Individual Strategy and Social Structure, Princeton, NJ: Princeton University Press. 
TABLE 1

Experimental treatments

\begin{tabular}{|c|c|c|}
\hline \multirow{2}{*}{ Audit Results on Neighbours? } & \multicolumn{2}{|c|}{ Filing Information on Neighbours? } \\
\cline { 2 - 3 } & No & Yes \\
\hline No & T1 & T2 \\
\hline Yes & T3 & T4 \\
\hline
\end{tabular}

TABLE 2

Selected summary statistics

\begin{tabular}{|c|c|c|c|c|c|}
\hline Variable & $\begin{array}{c}\text { Full } \\
\text { Sample }\end{array}$ & T1 & T2 & T3 & T4 \\
\hline Filing Rate & $\begin{array}{c}0.553 \\
(0.497)\end{array}$ & $\begin{array}{c}0.613 \\
(0.487)\end{array}$ & $\begin{array}{c}0.467 \\
(0.499)\end{array}$ & $\begin{array}{c}0.749 \\
(0.434)\end{array}$ & $\begin{array}{c}0.514 \\
(0.499)\end{array}$ \\
\hline Reporting Rate & $\begin{array}{c}0.494 \\
(0.497) \\
\end{array}$ & $\begin{array}{c}0.569 \\
(0.485) \\
\end{array}$ & $\begin{array}{c}0.432 \\
(0.501)\end{array}$ & $\begin{array}{c}0.635 \\
(0.470) \\
\end{array}$ & $\begin{array}{c}0.454 \\
(0.496) \\
\end{array}$ \\
\hline $\begin{array}{l}\text { Neighbour Filing Information Dummy } \\
(=1 \text { if information is disclosed, } 0 \\
\text { otherwise })\end{array}$ & $\begin{array}{c}0.667 \\
(0.471)\end{array}$ & 0.000 & 1.000 & 0.000 & 1.000 \\
\hline Neighbour Filing Percent Information (\%) & $\begin{array}{c}54.7 \\
(20.1)\end{array}$ & NA & $\begin{array}{c}46.5 \\
(15.8)\end{array}$ & NA & $\begin{array}{c}49.5 \\
(19.6)\end{array}$ \\
\hline $\begin{array}{l}\text { Neighbour Audit Information Dummy ( }=1 \\
\text { if information is disclosed, } 0 \text { otherwise) }\end{array}$ & $\begin{array}{c}0.629 \\
(0.483) \\
\end{array}$ & 0.000 & 0.000 & 1.000 & 1.000 \\
\hline $\begin{array}{l}\text { Neighbour Audit Results Information } \\
\text { (tokens of unpaid taxes plus penalties) }\end{array}$ & $\begin{array}{c}1.915 \\
(1.389) \\
\end{array}$ & NA & NA & $\begin{array}{c}2.572 \\
(1.451) \\
\end{array}$ & $\begin{array}{c}1.704 \\
(1.320)\end{array}$ \\
\hline Age (in years) & $\begin{array}{c}26.98 \\
(12.06)\end{array}$ & $\begin{array}{c}31.675 \\
(13.981)\end{array}$ & $\begin{array}{l}20.144 \\
(1.624)\end{array}$ & $\begin{array}{c}29.433 \\
(12.803)\end{array}$ & $\begin{array}{c}28.619 \\
(12.921)\end{array}$ \\
\hline Male Dummy (=1 if male, 0 if female) & $\begin{array}{c}0.434 \\
(0.496)\end{array}$ & $\begin{array}{c}0.400 \\
(0.491) \\
\end{array}$ & $\begin{array}{c}0.483 \\
(0.499)\end{array}$ & $\begin{array}{c}0.500 \\
(0.501) \\
\end{array}$ & $\begin{array}{c}0.392 \\
(0.488) \\
\end{array}$ \\
\hline $\begin{array}{l}\text { Student Dummy (=1 if student, } 0 \\
\text { otherwise) }\end{array}$ & $\begin{array}{c}0.715 \\
(0.452)\end{array}$ & $\begin{array}{c}0.500 \\
(0.500)\end{array}$ & 1.000 & $\begin{array}{c}0.666 \\
(0.472)\end{array}$ & $\begin{array}{c}0.635 \\
(0.481)\end{array}$ \\
\hline Observations & 4204 & 800 & 1160 & 600 & 1644 \\
\hline
\end{tabular}

Notes: Means are reported with standard deviations in parentheses. Filing Rate is the proportion of all observations in which the subject chose to file a form. Reporting Rate is the average across all observations of [Taxes Paid/Taxes Owed]. Neighbour Filing Information Dummy is a dummy variable equal to 1 if information on the filing behaviour of other members of the group is disclosed, 0 otherwise. Neighbour Filing Percent Information is the percentage of the other members in the group who filed a return, as reported to all members of the group. Neighbour Audit Information Dummy is a dummy variable equal to 1 if information on neighbour audit results is disclosed, 0 otherwise. Neighbour Audit Results Information is the amount in tokens of unpaid taxes and penalties paid by the other members of the group who were audited, as reported to all members of the group. Age is the age in years of the subject. Male Dummy is a dummy variable equal to 1 if the subject is male, 0 otherwise. Student Dummy is a dummy variable equal to 1 if the subject is a student, 0 otherwise. NA denotes "Not Applicable". 
TABLE 3

Estimation results: Filing and reporting behaviour

\begin{tabular}{|c|c|c|}
\hline & \multicolumn{2}{|c|}{ Dependent Variable } \\
\hline Independent Variables & Filing Rate & Reporting Rate \\
\hline Constant & $\begin{array}{c}0.8243 * * \\
(0.000)\end{array}$ & $\begin{array}{c}0.8058 * * \\
(0.000)\end{array}$ \\
\hline Income & $\begin{array}{c}0.0011 * * \\
(0.000)\end{array}$ & $\begin{array}{l}0.0001 \\
(0.000) \\
\end{array}$ \\
\hline Wealth & $\begin{array}{c}-0.0002 * * \\
(0.000)\end{array}$ & $\begin{array}{c}-0.0001 * * \\
(0.000)\end{array}$ \\
\hline Audit Probability & $\begin{array}{c}-0.0186 \\
(0.882) \\
\end{array}$ & $\begin{array}{c}0.3300 * * \\
(0.000)\end{array}$ \\
\hline Lag Own Audited Dummy & $\begin{array}{c}-0.0278 \\
(0.092)\end{array}$ & $\begin{array}{c}0.0245 * \\
(0.011)\end{array}$ \\
\hline Cost of Form & $\begin{array}{c}-0.0742^{* *} \\
(0.000)\end{array}$ & --- \\
\hline Neighbour Filing Information Dummy (T2 and T4) & $\begin{array}{c}-0.2202 * * \\
(0.000) \\
\end{array}$ & --- \\
\hline Lag Neighbour Filing Percent Information (T2 and T4) & $\begin{array}{c}0.1651 * * \\
(0.003)\end{array}$ & --- \\
\hline Neighbour Audit Information Dummy (T3 and T4) & --- & $\begin{array}{c}-0.0239 \\
(0.0426) \\
\end{array}$ \\
\hline Lag Neighbour Audit Results Information (T3 and T4) & --- & $\begin{array}{c}0.0106^{*} \\
(0.005) \\
\end{array}$ \\
\hline Prepare Own Taxes Dummy & $\begin{array}{c}-0.0181 \\
(0.493)\end{array}$ & $\begin{array}{c}-0.0384 \\
(0.336)\end{array}$ \\
\hline Age & $\begin{array}{c}-0.0016 \\
(0.231) \\
\end{array}$ & $\begin{array}{l}0.0012 \\
(0.511) \\
\end{array}$ \\
\hline Male Dummy & $\begin{array}{c}-0.0734 * * \\
(0.005)\end{array}$ & $\begin{array}{c}-0.1494 * * \\
(0.000)\end{array}$ \\
\hline Sample (Panels) & $3992(212)$ & $2197(190)$ \\
\hline Chi-squared & $151.69 * *$ & $52.42 * *$ \\
\hline
\end{tabular}

Notes: The dependent variables are Filing Rate (equal to 1 if yes, 0 otherwise) and Reporting Rate (equal to Taxes Paid/Taxes Owed), each defined at the individual subject level. Income is the subject's income in the round (in tokens). Wealth is the accumulated income net of taxes and penalties of the subject in the round (in tokens). Audit Probability is the probability that the subject will be audited in the round. Lag Own Audited Dummy is a dummy variable equal to 1 if the subject was audited in the previous round, 0 otherwise. Cost of Form is the cost in tokens of buying the tax form (equal to 0, 1, and 2 tokens). Neighbour Filing Information Dummy is a dummy variable equal to 1 if information on the filing behaviour of other members of the group is disclosed, 0 otherwise. Lag Neighbour Filing Percent Information is the percentage of the other members in the group who filed a return in the previous round, as reported to all members of the group. Neighbour Audit Information Dummy is a dummy variable equal to 1 if information on neighbour audit results is disclosed, 0 otherwise. Lag Neighbour Audit Results Information is the amount in tokens of unpaid taxes and penalties paid by the other members of the group who were audited in the previous round, as reported to all members of the group. Prepare Own Taxes Dummy is a dummy variable equal to 1 if the subject prepares his or her own taxes, 0 otherwise. Male Dummy is a dummy variable equal to 1 if the subject is male, 0 otherwise. Age is the age in years of the subject. Student Dummy is a dummy variable equal to 1 if the subject is a student, 0 otherwise. * and ** denote significance at the 5 and 1 percent levels, respectively. 
TABLE 4

Estimation results: Individual filing behaviour persistence

\begin{tabular}{|l|c|c|c|c|}
\hline & \multicolumn{3}{|c|}{ Dependent Variable: Filing Rate } \\
\hline $\begin{array}{c}\text { Independent } \\
\text { Variables }\end{array}$ & Model 1 & Model 2 & Model 3 & Model 4 \\
\hline Constant & $0.183^{* *}$ & $0.128^{* *}$ & $0.093^{* *}$ & $0.272^{* *}$ \\
& $(0.011)$ & $(0.012)$ & $(0.012)$ & $(0.011)$ \\
\hline Filed (Lagged 1) & $0.253^{* *}$ & $0.158^{* *}$ & $0.105^{* *}$ & \\
& $(0.015)$ & $(0.016)$ & $(0.017)$ & \\
\hline Filed (Lagged 2) & $0.401^{* *}$ & $0.346^{* *}$ & $0.271^{* *}$ & \\
& $(0.015)$ & $(0.015)$ & $(0.0164)$ & \\
\hline Filed (Lagged 3) & & $0.247 * *$ & $0.227^{* *}$ & \\
& & $(0.016)$ & $(0.016)$ & $0.483 * *$ \\
\hline Filed (Lagged 4) & & & $0.213 * *$ & $(0.015)$ \\
& & & $3356(212)$ & $3356(212)$ \\
\hline Sample (Panels) & $3780(212)$ & $3568(212)$ & 2133.40 & 1008.46 \\
\hline Chi-squared & 1660.53 & 1974.57 & $017)$ & \\
\hline
\end{tabular}

Notes: The dependent variable is Filing Rate (equal to 1 if yes, 0 otherwise), defined at the individual subject level. Filed (Lagged 1) is a dummy variable equal to 1 if the subject filed a return in the previous period, 0 otherwise; other lagged variables are defined similarly. * and ** denote significance at the 5 and 1 percent levels, respectively.

FIGURE 1

Individual filing rate behaviour

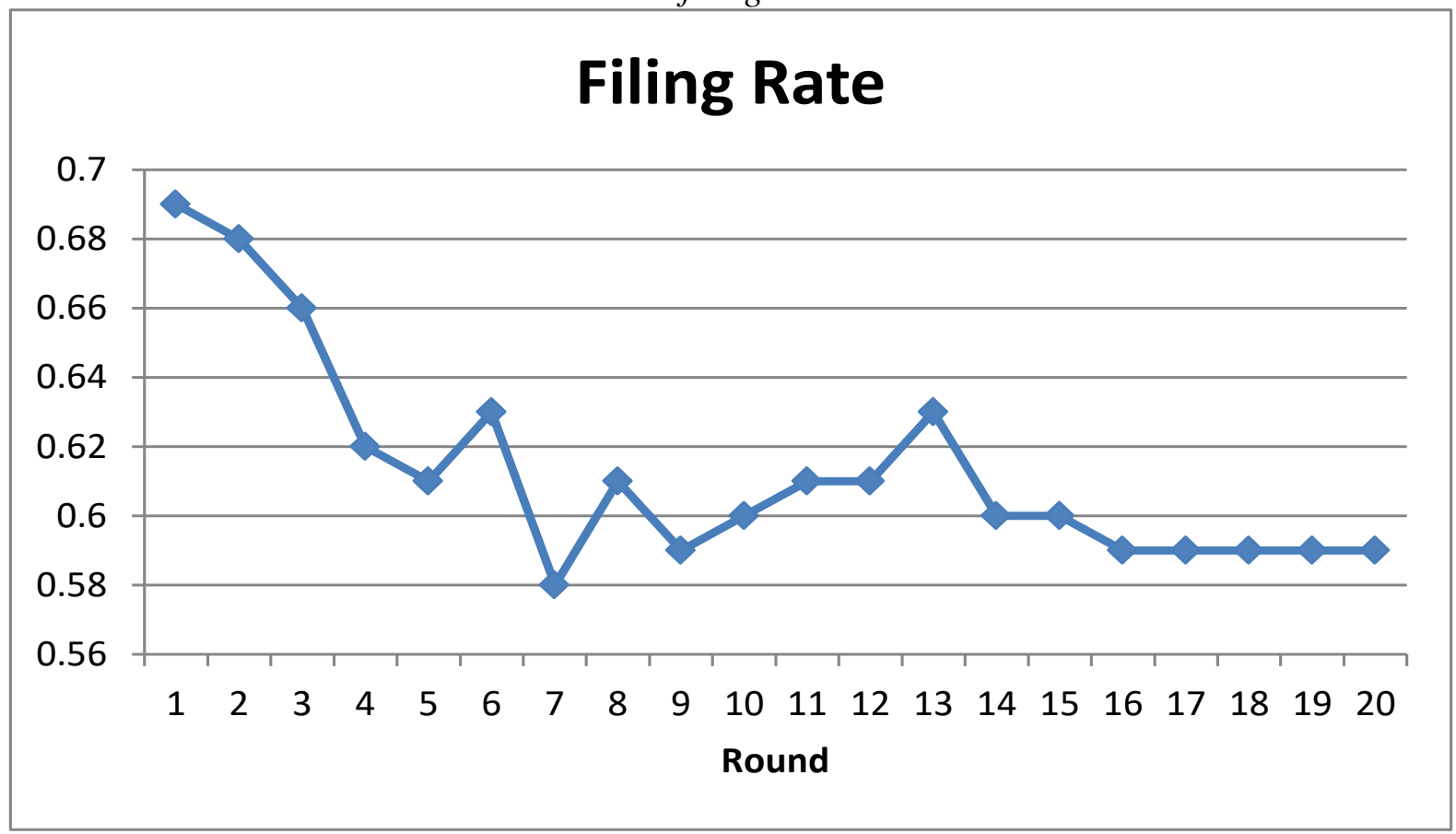

Notes: The figure plots by round the individual Filing Rate (equal to 1 if yes, 0 otherwise), averaged across all subjects and all treatments for a given round. 